\title{
Defining reef fish habitat utilization patterns in Hawaii: comparisons between marine protected areas and areas open to fishing
}

\author{
Alan M. Friedlander ${ }^{1, *}$, Eric Brown ${ }^{2,3}$, Mark E. Monaco ${ }^{4}$ \\ ${ }^{1}$ NOAA/NOS/NCCOS Center for Coastal Monitoring and Assessment, Biogeography Branch and the Oceanic Institute, \\ 41-202 Kalanianaole Highway Waimanalo, Hawaii 96795, USA \\ ${ }^{2}$ Hawaii Department of Land and Natural Resources, Division of Aquatic Resources, Wailuku, Hawaii 96793, USA \\ ${ }^{3}$ National Park Service, Kalaupapa National Historical Park, Hawaii 96742, USA \\ ${ }^{4}$ NOAA/NOS/NCCOS Center for Coastal Monitoring and Assessment, Biogeography Branch, \\ 1305 East West Highway, Silver Spring, Maryland 20190, USA
}

\begin{abstract}
Over the past 4 decades, Hawaii has developed a system of Marine Life Conservation Districts (MLCDs) to conserve and replenish marine resources. These MLCDs vary in size, habitat quality, and management regimes, providing an excellent opportunity to test hypotheses concerning marine protected area (MPA) design and function using multiple discreet sampling units. Digital benthic habitat maps for all MLCDs and adjacent habitats were used to evaluate the efficacy of existing MLCDs and adjacent habitats using a spatially explicit stratified random sampling design. Most fish assemblage characteristics (e.g. species richness, biomass, number of individuals) were highest in colonized hard bottom habitats (>10\% live coral cover), followed by uncolonized hard bottom habitats $(<10 \%$ live coral cover), macroalgae, and sand, respectively. Although biomass was low in sand habitats, apex predators accounted for $62 \%$ of the biomass on sand within MLCDs, highlighting the importance of this habitat in reserve design. Within habitats, values for assemblage characteristics were typically higher for MLCDs compared with adjacent areas, emphasizing the importance of protection from fishing irrespective of habitat. Rugosity explained much of the variability in species richness and biomass across all locations. Overall, MLCDs protected from fishing, with high habitat complexity and good habitat quality (e.g. high coral cover and low macroalgae cover), had higher values for most fish assemblage characteristics. Integrating mapping and assessment of reef fish habitat utilization patterns allowed for a robust approach to MPA evaluation and can help inform decisions about MPA design and effectiveness, as well as helping to define essential fish habitat and ecosystem function.
\end{abstract}

KEY WORDS: Marine protected areas - Fish habitat utilization - Habitat complexity · Hawaii • Overfishing Resale or republication not permitted without written consent of the publisher

\section{INTRODUCTION}

Coral reef fisheries resources are facing overexploitation and severe depletion worldwide (Jackson et al. 2001, Pandolfi et al. 2005) and Hawaii is no exception. Declines in fish abundance and size, particularly around the more populated areas of the state, are likely the result of years of chronic overfishing (Friedlander \& DeMartini 2002). Factors contributing to the decline of inshore fisheries include a growing human population, destruction or disturbance to habitat, introduction of new and overly efficient fishing techniques (e.g. inexpensive monofilament gill nets, SCUBA, GPS), and loss of traditional conservation practices (Friedlander et al. 2003a).

Diversity, quality, and areal extent of habitat are among the most important environmental determinants of coral reef fish distribution, abundance, and 
diversity (Bellwood \& Hughes 2001). Many reef fishes depend upon coral reefs and their adjacent habitats for food, as well as shelter (Parrish 1989, Beukers \& Jones 1997). Habitat complexity provides refuges and barriers that fragment the area, resulting in more abundant and heterogeneous assemblages (Sebens 1991).

In Hawaii, structurally complex habitats have been shown to harbor higher fish diversity and biomass compared to habitats with lower complexity (Friedlander \& Parrish 1998, Friedlander et al. 2003a). Loss and degradation of important habitats due to coastal development, sedimentation, pollution, and the impacts of non-native aquatic organisms have contributed to the decline of coral reef fishes in Hawaii, as well as the entire coral reef ecosystem (Hunter \& Evans 1995, Smith et al. 2002). Therefore, it is vital to understand the importance of habitat to ecosystem function and the changes that occur to these ecosystems as a result of the loss of habitat.

Ecosystem-based management requires a better understanding of the spatial patterns and processes that regulate ecosystem function, both to ensure the sustainability of fisheries and to maintain nonfisheries benefits of the ecosystem to society (Pikitch et al. 2004). In Hawaii, management units are typically on the scale of an island or the entire state and resource evaluation should therefore be conducted on a similar scale. A seascape perspective that couples the distribution of habitats and species habitat affinities at scales commensurate with ecosystem processes is valuable in understanding fish habitat utilization patterns (Kendall et al. 2003), and is useful in defining essential fish habitat (Clark et al. 2004) and biologically relevant boundaries for marine protected areas (MPAs) (Christensen et al. 2003, Friedlander et al. 2003b). Defining and understanding the mosaic of habitats and their connection within the ecosystem are critical if MPAs are to be effective in retaining productive populations within their borders (Appeldoorn et al. 2003, Christensen et al. 2003). A better understanding of the habitat requirements and life histories of the species of interest and the extent to which these habitats interact at larger spatial scales is critical if ecosystem science and management are to be effective (Sladek Nowlis \& Friedlander 2004, Monaco et al. 2005).

Hawaii established its first MPA in 1968; since then numerous protected areas have been established with varying levels of protection, ranging from complete 'no-take' areas to areas that allow a wide variety of activities to occur within their boundaries (Table 1). The objective of the present study was to take the first step in evaluating the effectiveness of existing MPAs in Hawaii by using a spatially explicit sampling design to define and quantify fish habitat utilization patterns across varying levels of habitat quality and protection from fishing. This approach will help to identify the ecological processes and management regimes that result in productive fish populations while providing policy makers with access to the necessary information to make informed decisions concerning MPA design and function at local, national, and international levels.

\section{MATERIALS AND METHODS}

Benthic habitat mapping. The National Oceanic and Atmospheric Administration (NOAA) acquired and visually interpreted orthorectified aerial photography, IKONOS satellite imagery, and hyperspectral imagery for the near-shore waters (to $30 \mathrm{~m}$ depth) for approximately $65 \%$ of the main Hawaiian Islands (MHI) (Coyne et al. 2003). Habitat features were delineated at a scale of 1:6000 with a minimum mapping unit (MMU) of $0.4 \mathrm{ha}$. Visual interpretation of the imagery was guided by a hierarchical classification scheme. Habitat types were defined in a collapsible hierarchy ranging from broad classes (unconsolidated sediment, macroalgae, coral reef hard bottom, and other), to more detailed categories (e.g. algae, volcanic rock boulders, pavement, etc.), and finally to percent cover of specific features (e.g. 50 to $90 \%$ macroalgae cover). In the present study, fish assemblage characteristics were analyzed at the habitat class level to clarify the ecological interpretation and management implications. The resulting digital benthic habitat maps (available at http://ccma.nos.noaa.gov/products/biogeography/ hawaii_cd/index.htm) were characterized by a high degree of spatial and thematic accuracy, which was calculated to be $90 \%$ (Kappa and Tau $=0.86$ ) for the major class level and $80 \%$ at the most detailed level of the classification scheme (Coyne et al. 2003).

Sample design. Sampling was conducted in Hawaii's 11 Marine Life Conservation Districts (MLCDs) (Fig. 1), the University of Hawaii Marine Laboratory Refuge (MLR), and adjacent, comparable habitats. For all analyses, the MLR was combined with the MLCDs, and all further references to MLCDs include the MLR. Locations for assessment were determined using a stratified random sampling approach where random points were assigned to each of 4 major habitat strata (colonized hard bottom [CHB], uncolonized hard bottom [UCH], unconsolidated sediment [UCS], and macroalgae [MAC]) using ArcView 3.2. Uncolonized hard bottom was defined as habitat having $<10 \%$ live coral cover. Within each major habitat type, sampling was further stratified by management regime (MLCD, Fisheries Management Area [FMA], and open access). FMAs comprised a heterogeneous group of manage- 
Table 1. Characteristics of the state of Hawaii Marine Life Conservation District (MLCD) and the University of Hawaii Marine Laboratory Refuge. Use: level of use as classified by Hawaii Division of Aquatic Resources (1992). Protection from fishing based on qualitative ranking of regulations, not on enforcement of these regulations. Percentage of total area allocated for permitted activities is listed for specific gear types and species

\begin{tabular}{|c|c|c|c|c|c|}
\hline Protected area & Hectares & $\begin{array}{c}\text { Year } \\
\text { established }\end{array}$ & Use & $\begin{array}{l}\text { Protection } \\
\text { from fishing }\end{array}$ & Permitted activities \\
\hline \multicolumn{6}{|l|}{ Oahu } \\
\hline Hanauma Bay & 40.8 & 1967 & High & High & Complete no-take \\
\hline Pupukea & 72.5 & $\begin{array}{l}1983^{\mathrm{a}} \\
(2003)\end{array}$ & Mod & Mod & $\begin{array}{l}\text { Pole-and-line from shore } \\
\text { Harvest of seaweed, Selar cumenophthalmus } \\
\text { (Nov-Dec) and Decapterus spp. (Aug-Sep) }\end{array}$ \\
\hline Waikiki & 31.4 & 1988 & High & High & Complete no-take \\
\hline $\begin{array}{l}\text { Moku o Loe, Univ. } \\
\text { of Hawaii Marine } \\
\text { Laboratory Refuge }\end{array}$ & 29.6 & 1967 & Low & High & Scientific collecting and propagation \\
\hline \multicolumn{6}{|l|}{ Hawaii } \\
\hline Kealakekua Bay & 123.6 & 1969 & High & Mod & $\begin{array}{l}\text { Hook and line: } 60 \% \\
\text { Throw net: } 60 \% \\
\text { Selar cumenophthalmus and Decapterus spp.: } 60 \% \\
\text { Crustaceans: } 60 \%\end{array}$ \\
\hline Lapakahi & 54.0 & 1979 & Low & Low & $\begin{array}{l}\text { Hook and line: } 90 \% \\
\text { Throw net: } 90 \% \\
\text { Lift net for Decapterus spp.: } 90 \%\end{array}$ \\
\hline Waialea Bay & 14.1 & 1985 & Low & Low & $\begin{array}{l}\text { Hook and line } \\
\text { Netting }\end{array}$ \\
\hline Old Kona Airport & 105.9 & 1992 & Mod & Mod & $\begin{array}{l}\text { Throw net from shore, pole and line from shore, } \\
\text { sea urchin collecting without scuba } \\
\text { from } 1 \text { Jun to } 1 \text { Oct }\end{array}$ \\
\hline Waiopae & 26.2 & 2003 & Mod & High & Complete no-take \\
\hline \multicolumn{6}{|l|}{ Lanai } \\
\hline Manele-Hulopoe & 111.7 & 1976 & Mod & Mod & $\begin{array}{l}\text { Hook and line from shore } \\
\text { All fishing except spear, trap, and net } \\
\text { (other than throw net): } 50 \%\end{array}$ \\
\hline \multicolumn{6}{|l|}{ Maui } \\
\hline Molokini Shoal & 35.7 & 1977 & High & High & Trolling in $60 \%$ of MLCD \\
\hline $\begin{array}{l}\text { Honolua-Mokuleia } \\
\text { Bay }\end{array}$ & 18.2 & 1978 & Mod & High & Complete no-take \\
\hline
\end{tabular}

ment areas that were designed to reduce user conflicts through gear restrictions or rotational closures.

Location points, in either latitude and longitude or Universal Transverse Mercator (UTM) coordinates, were downloaded into a GPS. Once in the field, 2 divers navigated to waypoints using GPS and conducted a single $25 \mathrm{~m}$ transect. The direction of each transect was determined randomly along the isobath of that GPS point except in cases where that direction caused the transect to traverse multiple habitats. In those situations, transects were run within a habitat polygon at a similar isobath stratum.

Fish sampling methodology. Fish assemblages at each location were quantified using standard underwater visual belt transect survey methods (Brock 1954). A diver swam a $25 \mathrm{~m}$ transect at a constant speed and identified to the lowest possible taxon all fishes visible within $2.5 \mathrm{~m}$ to either side of the centerline (125 $\mathrm{m}^{2}$ transect area). Swimming duration varied from 10 to $15 \mathrm{~min}$, depending on habitat complexity and fish abundance. At the beginning of the survey, the diver visualized out as far as possible to enumerate all individuals potentially leaving the sampling area. In this manner, we were able to partially account for the behavior that targeted species acquire in areas frequented by spearfishers (Kulbicki 1998). To ensure consistency in data collection, surveys were only conducted if visibility was greater than $10 \mathrm{~m}$ (i.e. double the transect width).

Total length (TL) of fish was visually estimated to the nearest $\mathrm{cm}$. Length estimates of fishes from censuses were converted to weight using the following lengthweight relationship: $W=\mathrm{aSL}^{\mathrm{b}}$, where the parameters $\mathrm{a}$ and $\mathrm{b}$ are constants for the allometric growth equa- 


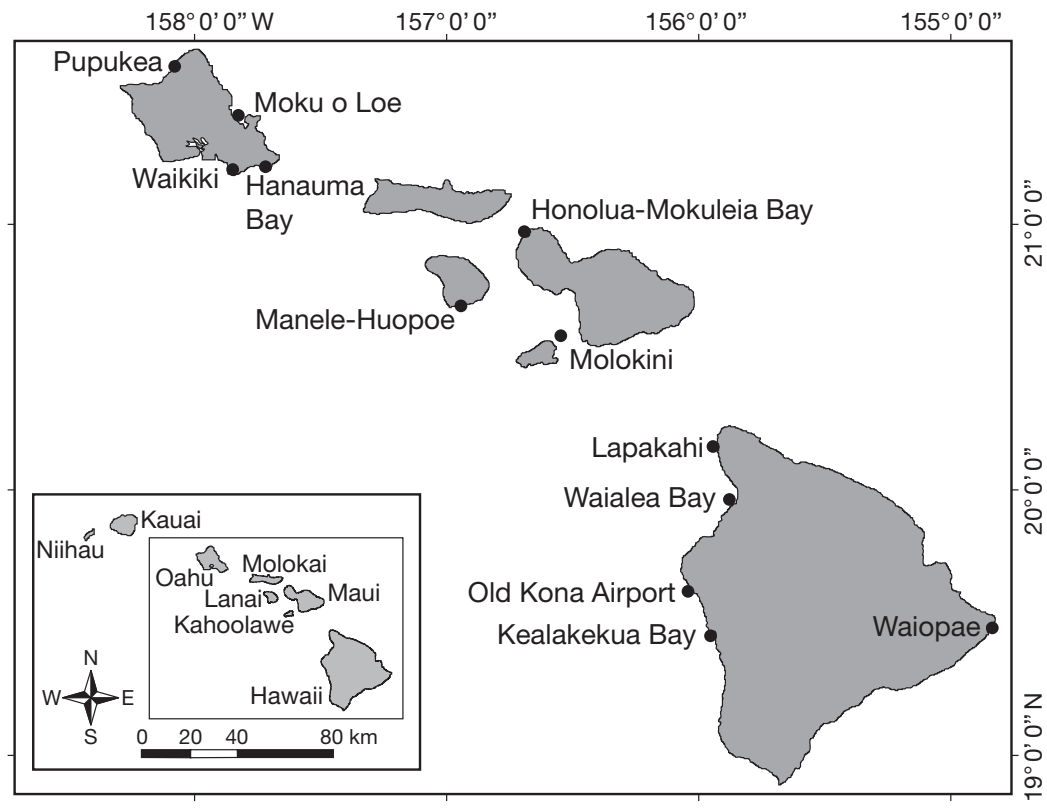

Fig. 1. Locations of Marine Life Conservation Districts (MLCDs) and Moku o Loe, the University of Hawaii Marine Laboratory Refuge (MLR) sample sizes versus power. The sample size at which further increases in number of replicates does not substantially increase power (decreasing SEM) is taken as the minimum number of samples.

For number of species per transect, high and low SEM began to level off and converge at ca. 4 samples in the CHB and UCS habitats and ca. 8 samples for the MAC and $\mathrm{UCH}$ habitats. For number of individuals per transect, high and low SEM began to converge at 6 samples in the UCS habitat and 9 to 10 samples in the $\mathrm{CHB}, \mathrm{UCH}$, and $\mathrm{MAC}$ habitats. Given this set of results, 9 to 10 samples per habitat appeared to be adequate to control the SEM for number of individuals and number of species per transect and was the targeted sample size used per habitat and management stratum in each survey area.

Benthic survey techniques. On completion of the fish survey, benthic cover tion, SL is standard length in $\mathrm{mm}$, and $W$ is weight in grams. TL was converted to SL by multiplying SL to TL-fitting parameters obtained from FishBase (www.fishbase.org) and other published and webbased sources. Length-weight fitting parameters were available for 150 species commonly observed on visual fish transects in Hawaii (Hawaii Cooperative Fishery Research Unit unpubl. data). In the cases where length-weight information did not exist for a given species, the parameters from similar bodied congeners were used. All biomass estimates were converted to metric tons per hectare ( $\mathrm{t} \mathrm{ha}^{-1}$ ) to facilitate comparisons with other studies in Hawaii. Fish taxa were categorized into 3 trophic guilds (herbivores, secondary consumers, and apex predators) according to various published sources (e.g. Friedlander \& DeMartini 2002) and FishBase (www.fishbase.org). Estimates of the abundance of apex predators from visual transects often have high variance associated with them, so some care is necessary when interpreting the results from this trophic group.

Fish sample size analysis. A pilot study was conducted in the Waikiki area to determine optimal sample size to adequately characterize the number of species and number of individuals per transect among the 4 major habitat types for each management regime in each study area. A technique developed by Bros \& Cowell (1987) using the standard error of the mean (SEM) to resolve statistical power was used for this analysis. This method uses a Monte Carlo simulation procedure to generate a range of was assessed along the same $25 \mathrm{~m}$ transect line. During the first survey period (Waikiki area), digital video transects were used to measure coral species richness and percent coverage, but all subsequent surveys were conducted using the in situ planar point intercept quadrat method (Reed 1980) due to the long post-survey processing time (ca. $2 \mathrm{hr}$ for 1 transect) and low taxonomic resolution of some substrate categories (e.g. macroalgae) using video. It should be noted that previous comparisons between methods showed no statistical difference in the overall benthic assemblage structure (Brown 2004).

For the video method, each transect was videotaped from a perpendicular angle at a height of $0.5 \mathrm{~m}$ above the substrate. Total area sampled along each transect was $12.8 \mathrm{~m}^{2}$. Image analysis was conducted using 20 randomly selected non-overlapping video frames from each transect with 50 randomly selected points per frame. Based on previous analysis, this level of effort adequately characterized the substrate (Brown et al. 2004). Percent cover was tabulated for coral (by species), macroinvertebrates, and other benthic substrate types (coralline algae, turf algae, macroalgae, and sand).

For the in situ visual quadrats, each transect was stratified into $5 \mathrm{~m}$ segments with a single quadrat randomly allocated within each segment $(\mathrm{N}=5)$. Twentyfive randomly selected intersections were marked on a $1 \mathrm{~m}^{2}$ quadrat grid and used for substrate identification within each $5 \times 5 \mathrm{~m}$ segment $(\mathrm{n}=125$ points per transect). Sample size was optimized by comparing 
standard deviation versus sampling time as a function of number of points per quadrat $(10,25$, or 50$)$. Each point-intersection was identified using substrate categories of sand, coralline algae, turf algae, macroalgae, and coral. Coral and macroinvertebrates were identified to species level. Limitations of in situ methodology precluded taxonomic resolution of algae to species, so algae were identified to genera. Percent cover values for each substrate category and coral species were derived by dividing the number of occupied points by the total number of intersections (25) within each quadrat.

Rugosity methods. To measure reef rugosity or surface relief, a small link chain $(1.3 \mathrm{~cm}$ per link) was draped along the length of the centerline of each transect (Risk 1972). Care was taken to ensure that the chain followed the contour of all natural fixed surfaces directly below the transect centerline. A ratio of distance along the reef surface contour (cd) to linear horizontal distance (ld) gave an index of spatial relief or rugosity $(\mathrm{r}): \mathrm{r}=\mathrm{cd} / \mathrm{ld}$.

Data analysis. For the purposes of this study, results focused on the entire fish assemblage rather than individual fish species. Number of individuals and biomass were $\ln (x+1)$ transformed prior to statistical analysis to conform to the assumptions of normality and homogeneity of variances (Zar 1999). Percent substrate cover data were arcsine-square root transformed prior to statistical analyses (Zar 1999). Non-metric multi dimensional scaling (MDS) analysis coupled with an analysis of similarities (ANOSIM) test were conducted using PRIMER v. 5 (Clarke \& Gorley 2001) to examine fish biomass among habitats and management regimes. The data matrix consisted of mean fish biomass by species for each major habitat within each management strata at each overall location. A BrayCurtis similarity matrix was created from the $\ln (x+1)$ transformed mean fish biomass matrix prior to conducting the MDS.

Fish assemblage characteristics among habitat types were compared using a Kruskal-Wallis rank sum test with Dunn's test for unplanned multiple comparisons. Within habitat types, fish assemblage characteristics were compared using Wilcoxon rank sum tests. Comparisons of individual trophic groups between management regimes and within habitat types was also compared using Wilcoxon rank sum tests.

To evaluate size-related differences between management regimes within habitats, we developed size spectra for each habitat and management strata (Dulvy et al. 2004). Size spectra were based on mean numerical density (no. ha ${ }^{-1}$ ) for each $5 \mathrm{~cm}$ TL size class (10 to $65 \mathrm{~cm}$ for $\mathrm{CHB}$ and $\mathrm{UCH}, 10$ to $50 \mathrm{~cm}$ for MAC and UCS), and described using least squares regression to relate $\log _{10}$-transformed numerical densities to body length. Size spectra were standardized by rescaling the midpoint of the length range to zero to remove the correlation between the slopes and intercept (Dulvy et al. 2004). Within each habitat type, an ANCOVA was conducted between the 2 regression models (MLCD and open area). Differences in the least square means (LSM) between management regimes were tested using Tukey's HSD.

Stepwise multiple regression analyses were conducted to assess the importance of various independent variables on fish assemblage characteristics (species richness, number of individuals, and biomass). Independent variables included percent cover of live coral, macroalgae, sand, turf algae, as well as rugosity, depth, and whether the transect was protected from fishing (protected $=$ MLCDs). Percent cover data were arcsine-square root transformed prior to analyses. Probability to enter the model was 0.25 and probability to leave was 0.10 . Model selection criterion was based on Mallows' $C_{p}$ criterion, an alternative measure of total squared error defined as:

$$
C_{p}=\left(\mathrm{SSE}_{p} / s^{2}\right)-(\mathrm{N}-2 p)
$$

where $s^{2}$ is the mean-square error (MSE) for the full model and $\mathrm{SSE}_{p}$ is the error sum of squares for the fitted subset regression model with $p$ parameters. If $C_{p}$ is graphed with $p$, Mallows (1973) recommended choosing the model where $C_{p}$ first approached $p$. The Variance Inflation Factor (VIF) was used to measure the possible collinearity among explanatory variables where a value $>10$ is indicative of collinearity (Kleinbaum et al. 1988). The UCS habitat was excluded from the analysis with only MLCDs since it was not found in all protected areas.

\section{RESULTS}

\section{Sampling effort}

A total of 939 spatially independent surveys were conducted between 22 January 2002 and 22 December 2004 (Table 2). Sampling depth averaged $6.2 \pm$ $5.2 \mathrm{~m}(\mathrm{SD})$ and ranged from 0.5 to $31.8 \mathrm{~m}$. On average, ca. $9.3 \pm 5.6 \mathrm{~km}$ of linear shoreline was surveyed for each protected area and its adjacent habitat. Of the total, $40 \%$ were in $\mathrm{CHB}, 29 \%$ were in $\mathrm{UCH}, 20 \%$ were in UCS, and $11 \%$ were in MAC. MLCDs comprised $40 \%$ of the samples, while $52 \%$ were conducted in areas open to fishing, with the remaining $8 \%$ in FMAs. FMAs were excluded from further analyses owing to this small sample size, uneven distribution among the protected areas, and a lack of representative habitat types, resulting in an unbalanced design. 
Table 2. Sample allocation among habitat types and management regimes. CHB: colonized hard bottom; UCH: uncolonized hard bottom; MAC: macroalgae; UCS: unconsolidated sediments (sand); FMA: Fisheries Management Area; MLCD: marine Life Conservation District

\begin{tabular}{|lcrrrrr}
\hline \multirow{2}{*}{ Habitat } & Management & $\mathrm{N}$ & \multirow{2}{*}{ Avg. $( \pm \mathrm{SD})$} & \multicolumn{2}{c|}{ Depth $(\mathrm{m})-$} \\
& & & & & Min. & Max. \\
\hline CHB & FMA & 41 & $8.14(3.29)$ & 1.52 & 16.46 \\
& MLCD & 163 & $5.67(3.87)$ & 0.61 & 19.81 \\
& Open & 169 & $5.67(3.81)$ & 0.49 & 15.85 \\
UCH & FMA & 21 & $3.06(1.46)$ & 0.91 & 5.79 \\
& MLCD & 110 & $3.85(3.05)$ & 0.49 & 14.94 \\
& Open & 142 & $5.53(4.39)$ & 0.49 & 19.11 \\
MAC & FMA & 9 & $0.93(0.22)$ & 0.46 & 1.22 \\
& MLCD & 21 & $1.20(0.84)$ & 0.61 & 4.57 \\
\multirow{2}{*}{ UCS } & Open & 76 & $5.08(6.47)$ & 0.61 & 22.86 \\
& FMA & 10 & $13.26(3.56)$ & 7.92 & 18.29 \\
\multirow{2}{*}{ Total } & MLCD & 79 & $8.45(5.53)$ & 1.52 & 32.00 \\
& Open & 98 & $8.47(6.35)$ & 0.61 & 24.08 \\
& & 939 & & & \\
\hline
\end{tabular}

Table 3. Comparisons of fish assemblage characteristics among management regimes by major habitat type (defined in Table 2 ). Values are means $( \pm \mathrm{SD})$ for all transects in each stratum. CHB: $\mathrm{N}_{\mathrm{MLCD}}=163, \mathrm{~N}_{\text {Open }}=169 ; \mathrm{UCH}: \mathrm{N}_{\mathrm{MLCD}}=$ $110, \mathrm{~N}_{\text {Open }}=142 ;$ MAC: $\mathrm{N}_{\text {MLCD }}=21, \mathrm{~N}_{\text {Open }}=76 ;$ UCS: $\mathrm{N}_{\mathrm{MLCD}}=79, \mathrm{~N}_{\text {Open }}=98$; $Z$ : statistical results of Mann-Whitney rank sum tests

\begin{tabular}{|c|c|c|c|c|c|}
\hline Habitat & MLCD & Open & $\begin{array}{c}\text { Percent } \\
\text { difference }\end{array}$ & $Z$ & $\mathrm{p}$ \\
\hline \multicolumn{6}{|c|}{ Species richness } \\
\hline $\mathrm{CHB}$ & $21.15(0.47)$ & $18.58(0.46)$ & 13.83 & 3.61 & $<0.001$ \\
\hline $\mathrm{UCH}$ & $18.44(7.10)$ & $12.85(7.05)$ & 43.50 & 5.64 & $<0.001$ \\
\hline MAC & $6.62(4.65)$ & $5.13(5.00)$ & 29.04 & 1.77 & 0.076 \\
\hline UCS & $2.33(3.34)$ & $1.06(1.68)$ & 119.81 & 3.10 & 0.002 \\
\hline \multicolumn{6}{|c|}{ Numbers (no. m²) } \\
\hline $\mathrm{CHB}$ & $1.16(0.69)$ & $1.09(0.69)$ & 5.95 & 1.22 & 0.224 \\
\hline $\mathrm{UCH}$ & $0.82(0.46)$ & $0.58(0.46)$ & 41.82 & 4.03 & $<0.001$ \\
\hline MAC & $0.27(0.22)$ & $0.16(0.23)$ & 68.10 & 3.04 & 0.002 \\
\hline UCS & $0.05(0.09)$ & $0.02(0.05)$ & 133.33 & 2.62 & 0.009 \\
\hline \multicolumn{6}{|c|}{ Biomass (t ha $\left.{ }^{-1}\right)$} \\
\hline $\mathrm{CHB}$ & $0.97(0.99)$ & $0.50(0.37)$ & 94.00 & 6.66 & $<0.001$ \\
\hline $\mathrm{UCH}$ & $0.87(0.80)$ & $0.30(0.38)$ & 190.00 & 7.44 & $<0.001$ \\
\hline MAC & $0.12(0.21)$ & $0.04(0.07)$ & 200.00 & 1.60 & 0.110 \\
\hline UCS & $0.18(0.70)$ & $0.02(0.02)$ & 800.00 & 4.23 & $<0.001$ \\
\hline
\end{tabular}

\section{Fish assemblage characteristics}

Fish assemblage characteristics varied greatly by habitat type and management strata (Table 3). Species richness was significantly different among the 4 major habitat types $(\mathrm{H}=515.7, \mathrm{p}<0.001, \mathrm{CHB}>\mathrm{UCH}>$ $\mathrm{MAC}>\mathrm{UCS}$ ) with $\mathrm{CHB}$ averaging $19.8 \pm 6.2$ (SD) species per transect $\left(125 \mathrm{~m}^{2}\right)$ compared to UCS habitats which averaged only $1.6 \pm 2.6$ species. Within all habitat types except MAC, species richness was signif- icantly higher in MLCDs compared with areas open to fishing (Table 3).

Significant differences among all 4 habitat types were detected for number of individuals $(\mathrm{H}=520.8, \mathrm{p}<$ 0.001, $\mathrm{CHB}>\mathrm{UCH}>\mathrm{MAC}>\mathrm{UCS})$. The average number of ind. $\mathrm{m}^{-2}$ ranged from $1.16 \pm 0.69(\mathrm{SD})$ in $\mathrm{CHB}$ within MLCDs to $0.03( \pm 0.07 \mathrm{SD})$ in UCS open to fishing. CHB was the only habitat type that did not show a significant difference in number of individuals between MLCDs and fished areas.

Fish biomass differed significantly among the 4 major habitat types except between MAC and UCS $(\mathrm{H}=$ 446.2, $\mathrm{p}<0.001, \mathrm{CHB}>\mathrm{UCH}>\mathrm{MAC}$ $=$ UCS). MLCDs had significantly higher biomass than fished areas for all habitat types except MAC. Biomass was $94 \%$ higher in CHB habitats within MLCDs compared to areas open to fishing. The largest differences in biomass between management regimes within a single habitat type occurred in UCS, where biomass in the MLCDs was 8 times higher than areas open to fishing. The midpoint height of the numerical densityto-body size relationship (i.e. abundance at the mid-point of the length distribution) was significantly higher in MLCDs compared to areas open to fishing for all habitat types (Table 4, Fig. 2).

\section{Multivariate comparison of fish assemblages}

Comparison of fish assemblages (based on biomass) among all locations showed strong correlations with habitat (Fig. 3). ANOSIM found significant differences in assemblage biomass among all habitat types (ANOSIM Global R = 0.51, p < 0.001). Pairwise comparisons among habitat types found fish assemblages in the $\mathrm{CHB}$ and $\mathrm{UCH}$ habitats to be most similar in structure (Table 5). Much of the MAC habitat sampled was macroalgae growing on hard substrate, and as a result showed similarities with the other hard bottom assemblages. The fish assemblages in the UCS habitats were highly variable but distinct from the other habitat types. 
Table 4. ANCOVA comparing size spectra $\left(\log _{10}\right.$ numerical densities vs. body length class) between management regimes (MLCD vs. Open) for each habitat type (defined in Table 2). Least square means (LSM) compared using Tukey's $\operatorname{HSD}(\alpha=0.05)$

\begin{tabular}{|c|c|c|c|c|c|}
\hline $\mathrm{CHB}$ & $\mathrm{R}^{2}=0.97$ & & & & LSM comparison \\
\hline Source & $\mathrm{df}$ & MS & $F$ & $\mathrm{p}$ & \\
\hline Model & 2 & 17.5 & 346.9 & $<0.001$ & \\
\hline Length class & 1 & 34.5 & 682.5 & $<0.001$ & \\
\hline Management & 1 & 0.6 & 11.3 & 0.003 & MLCD $(1.9)>$ Open $(1.6)$ \\
\hline Error & 21 & 0.5 & & & \\
\hline $\mathrm{UCH}$ & $\mathrm{R}^{2}=0.95$ & & & & \\
\hline Source & $\mathrm{df}$ & MS & $F$ & $\mathrm{p}$ & \\
\hline Model & 2 & 14.5 & 212.0 & $<0.001$ & \\
\hline Length class & 1 & 27.9 & 407.6 & $<0.001$ & \\
\hline Management & 1 & 1.1 & 16.4 & $<0.001$ & MLCD (1.9) > Open (1.5) \\
\hline Error & 21 & 0.5 & & & \\
\hline MAC & $\mathrm{R}^{2}=0.92$ & & & & \\
\hline Source & df & MS & $F$ & $\mathrm{p}$ & \\
\hline Model & 2 & 6.4 & 90.9 & $<0.001$ & \\
\hline Length class & 1 & 12.2 & 173.5 & $<0.001$ & \\
\hline Management & 1 & 0.6 & 8.3 & 0.01 & MLCD $(1.7)>$ Open $(1.3)$ \\
\hline Error & 21 & 0.1 & & & \\
\hline UCS & $\mathrm{R}^{2}=0.84$ & & & & \\
\hline Source & df & MS & $F$ & $\mathrm{p}$ & \\
\hline Model & 2 & 3.1 & 39.0 & $<0.001$ & \\
\hline Length class & 1 & 5.5 & 5.1 & $<0.001$ & \\
\hline Management & 1 & 1.0 & 1.1 & 0.002 & $\operatorname{MLCD}(1.4)>$ Open $(0.9)$ \\
\hline Error & 17 & 0.1 & & & \\
\hline
\end{tabular}

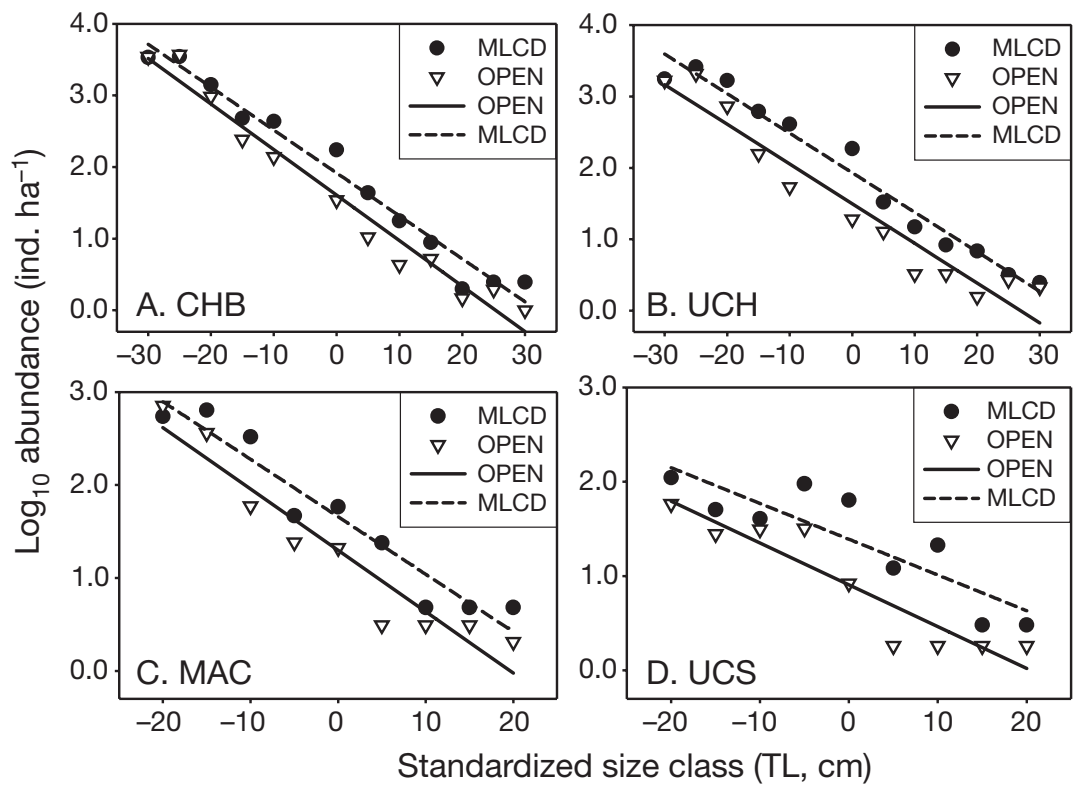

Fig. 2. Size spectra of $\log _{10}$-transformed number of fish ha ${ }^{-1}$ by standardized size class (total length, TL) for all fishes, in sites open to fishing and in MLCDs by habitat type: (A) colonized hard bottom (CHB); (B) uncolonized hard bottom $(\mathrm{UCH}) ;(\mathrm{C})$ macroalgae (MAC); (D) unconsolidated sediments (sand) (UCS). ANCOVA results in Table 4
Fish assemblages (based on biomass) differed significantly between MLCDs and open areas for CHB (ANOSIM Global $\mathrm{R}=0.15, \mathrm{p}=0.009$ ) and $\mathrm{UCH}$ (ANOSIM Global R $=0.317, \mathrm{p}=0.004$ ) habitats. Assemblages for the 2 management regimes were similar for UCS (ANOSIM Global $\mathrm{R}=0.07, \mathrm{p}=0.217$ ) and MAC (ANOSIM Global $\mathrm{R}=0.182$, $\mathrm{p}=0.381$ ) habitats, although a limited number of sampling locations in MAC made statistical comparisons problematic.

\section{Factors influencing fish assemblages}

Rugosity accounted for $50 \%$ of the variability in species richness among all sampling locations (Table 6A). The presence of sand and macroalgae had negative relationships with species richness and explained an additional 13 and $3 \%$ of the variability, respectively. Protection from fishing only accounted for an additional $1 \%$ of the variance in species richness. Sand had a negative relationship with number of individuals, explaining nearly $57 \%$ of the variability (Table 6B). Rugosity contributed an additional $10 \%$ to number of individuals, followed by protection from fishing $(1 \%)$, live coral cover $(0.8 \%)$, and turf algae $(0.6 \%)$. Approximately $34 \%$ of the variability in biomass was explained by rugosity, with an additional $7 \%$ explained by protection from fishing (Table 6C). Sand and macroalgae displayed negative relationships with biomass and explained an additional 4 and $2 \%$ of the variability, respectively.

Rugosity was the most important parameter in explaining variability in species richness, and biomass, and was also important for number of individuals. As a result, rugosity was used as a covariate to examine the importance of management regimes in structuring fish assemblages. ANCOVA revealed significantly higher fish biomass in protected areas compared to open areas with similar rugosity $\left(F_{1,21}=24.0, \mathrm{p}<\right.$ $0.001, \mathrm{R}^{2}=0.78$, LSM: MLCD > Open, Fig. 4). 


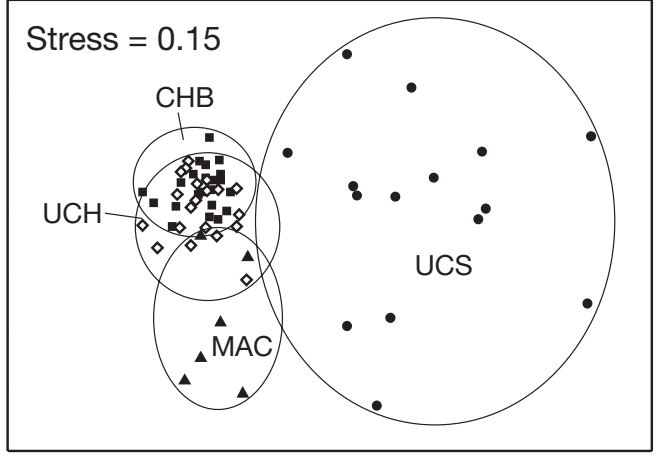

Fig. 3. Nonmetric multi-dimensional scaling plot of sampling locations by habitat type (defined in Table 2). Input values are mean fish biomass $\left(\mathrm{t} \mathrm{ha}^{-1}\right)$ by species for each habitat type, $\mathrm{N}=64$. Circles encompass locations with similar habitat types showing high concordance of fish biomass levels within $\mathrm{CHB}$ and $\mathrm{UCH}$ habitats and low concordance within UCS habitats

Table 5. Similarities of fish assemblages (based on biomass) among habitat types (defined in Table 2). ANOSIM Global $\mathrm{R}=$ $0.51, \mathrm{p}<0.001$. Pairwise tests results

\begin{tabular}{|lccc|}
\hline Habitat comparison & R statistic & p & Similarity \\
\hline CHB and UCH & 0.126 & 0.003 & Most \\
UCS and MAC & 0.415 & 0.001 & \\
UCH and MAC & 0.643 & 0.001 & \\
UCH and UCS & 0.725 & 0.001 & \\
CHB and UCS & 0.753 & 0.001 & \\
CHB and MAC & 0.858 & 0.001 & Least \\
\hline
\end{tabular}

Table 6. Stepwise multiple regression analyses for fish assemblage characteristics among all habitat types (defined in Table 2). Probability to enter the model was 0.25 and probability to leave was 0.10 . Model selection criterion based on Mallow's $C_{p}$ criterion for selecting a model. Percent cover data were arcsin square root transformed prior to analyses. Biomass and number of individuals $\ln (x+1)$ transformed for statistical analyses. $p$ : no. variables; VIF: Variance Inflation Factor

\begin{tabular}{|lrrrrrrr|}
\hline Parameter & Estimate & Seq SS & \multirow{2}{*}{$F$ ratio } & $\mathrm{R}^{2}$ & $C_{p}$ & $p$ & VIF \\
\hline (A) Species richness & & & & & & \\
Rugosity & 0.54 & 41212.54 & 149.93 & 0.502 & 601.16 & 2 & 2.34 \\
Sand & -15.34 & 10452.88 & 82.39 & 0.629 & 211.28 & 3 & 4.38 \\
Macroalgae & -7.89 & 2558.54 & 24.40 & 0.661 & 117.36 & 4 & 1.29 \\
Management & -1.26 & 989.38 & 49.84 & 0.673 & 82.27 & 5 & 1.07 \\
Depth & 0.21 & 1032.89 & 33.31 & 0.685 & 45.55 & 6 & 1.20 \\
Turf algae & 7.79 & 422.52 & 33.65 & 0.690 & 31.71 & 7 & 2.52 \\
Coral cover & 10.83 & 685.77 & 25.71 & 0.699 & 8.00 & 8 & 3.16 \\
(B) Number of individuals & & & & & & \\
Sand & -1.85 & 543.85 & 120.95 & 0.567 & 404.89 & 2 & 3.73 \\
Rugosity & 0.05 & 102.47 & 107.68 & 0.674 & 77.63 & 3 & 2.33 \\
Management & -0.10 & 9.63 & 29.49 & 0.684 & 48.68 & 4 & 1.03 \\
Coral cover & 1.47 & 8.69 & 44.13 & 0.693 & 22.75 & 5 & 2.89 \\
Turf algae & 0.63 & 6.14 & 19.76 & 0.699 & 5.02 & 6 & 2.42 \\
(C) Biomass & & & & & & & \\
Rugosity & 0.02 & 35.41 & 141.24 & 0.338 & 235.79 & 2 & 1.60 \\
Management & -0.09 & 7.26 & 115.92 & 0.408 & 115.54 & 3 & 1.05 \\
Sand & -0.49 & 4.53 & 102.76 & 0.451 & 41.30 & 4 & 1.61 \\
Macroalgae & -0.45 & 2.45 & 41.29 & 0.474 & 2.14 & 5 & 1.11 \\
\hline
\end{tabular}

\section{Trophic composition}

Overall, primary consumers accounted for $62 \%$ of total fish biomass, followed by secondary consumers $(29 \%)$ and apex predators (9\%), respectively. Biomass of all trophic groups was significantly higher in the MLCDs compared with open areas for $\mathrm{CHB}, \mathrm{UCH}$ and UCS habitats (Table 7A,B,D). For primary consumers, differences in biomass between the MLCDs and open areas were $51 \%$ and $27 \%$ for $\mathrm{CHB}$ and $\mathrm{UCH}$, respectively. As to be expected, densities of this trophic group were low in UCS, accounting for only $14 \%$ of the biomass in the MLCDs and $<1 \%$ in the open areas.

Apex predators showed the largest differences in biomass between MLCDs and open areas for these 3 habitat types. The most pronounced differences were in UCS, where apex predators accounted for the majority of the biomass in the MLCDs $(62 \%)$, but $<1 \%$ in the open areas. Numerical density of fishes was low overall in this habitat type and the few large apex predators observed may bias these results. In $\mathrm{CHB}$, apex predators accounted for $12 \%$ of the total biomass within MLCDs but only $3 \%$ within open areas. Biomass of apex predators was low overall in $\mathrm{UCH}$ but still significantly higher $(\mathrm{p}<0.001)$ in MLCDs compared to open areas.

Within MAC habitats, no significant differences were found in biomass between any trophic groups, although primary consumers were 9 times more 
Table 7. Trophic comparisons of fish biomass ( $\mathrm{tha}^{-1}$ ) among management regimes by major habitat type (defined in Table 2 ). Values are means $( \pm \mathrm{SD})$ for all transects in each stratum. $Z=$ statistical results of Mann-Whitney rank sum tests

\begin{tabular}{|c|c|c|c|c|c|c|}
\hline Trophic & $\begin{array}{l}\text { Mean } \\
\text { (SD) }\end{array}$ & $\begin{array}{c}\text { Percentage } \\
\text { of total }\end{array}$ & $\begin{array}{cc}\text { Mean } & \text { Pel } \\
(\mathrm{SD}) & \end{array}$ & $\begin{array}{l}\text { rcentage } \\
\text { of total }\end{array}$ & $Z$ & $\mathrm{p}$ \\
\hline (A) $\mathrm{CHB}$ & \multicolumn{2}{|c|}{$\mathrm{MLCD}, \mathrm{N}=163$} & \multicolumn{2}{|c|}{ Open, $\mathrm{N}=169$} & & \\
\hline Primary & $0.59(0.67)$ & 60.9 & $0.29(0.28)$ & 58.7 & 5.92 & $<0.0001$ \\
\hline Secondary & $0.26(0.24)$ & 26.5 & $0.19(0.18)$ & 37.9 & 3.56 & $<0.0001$ \\
\hline Apex & $0.12(0.48)$ & 12.6 & $0.02(0.10)$ & 3.4 & 4.76 & $<0.0001$ \\
\hline (B) UCH & \multicolumn{2}{|c|}{$\mathrm{MLCD}, \mathrm{N}=110$} & \multicolumn{2}{|c|}{ Open, $\mathrm{N}=142$} & & \\
\hline Primary & $0.67(0.70)$ & 76.1 & $0.19(0.28)$ & 62.5 & 7.36 & $<0.0001$ \\
\hline Secondary & $0.19(0.21)$ & 21.3 & $0.11(0.16)$ & 37.0 & 4.31 & $<0.0001$ \\
\hline Apex & $0.02(0.08)$ & 2.6 & $<0.01(0.01)$ & 0.5 & 4.54 & $<0.0001$ \\
\hline (C) MAC & \multicolumn{2}{|c|}{ MLCD, $N=21$} & \multicolumn{2}{|c|}{ Open, $\mathrm{N}=76$} & & \\
\hline Primary & $0.09(0.16)$ & 75.0 & $0.01(0.05)$ & 37.3 & 1.68 & 0.09 \\
\hline Secondary & 0.03 (0.05) & 25.0 & $0.02(0.04)$ & 59.9 & 0.64 & 0.52 \\
\hline Apex & $<0.01(<0.01)$ & 1) $<0.1$ & $<0.01(<0.01)$ & ) 2.8 & 0.90 & 0.36 \\
\hline (D) UCS & \multicolumn{2}{|c|}{ MLCD, $N=79$} & \multicolumn{2}{|c|}{ Open, $\mathrm{N}=98$} & & \\
\hline Primary & $0.03(0.10)$ & 14.5 & $<0.01(0.0)$ & 0.2 & 3.60 & $<0.0001$ \\
\hline Secondary & $0.04(0.13)$ & 23.4 & $0.02(0.11)$ & 92.8 & 3.30 & $<0.0001$ \\
\hline Apex & $0.11(0.65)$ & 62.2 & $<0.01(0.01)$ & 7.0 & 3.42 & $<0.0001$ \\
\hline
\end{tabular}

also had high macroalgae cover dominated by cyanobacteria that was likely associated with cesspools from adjacent shoreline homes.

\section{Factors influencing fish assemblages among MLCDs}

Within the protected areas, depth explained nearly $64 \%$ of the variance in species richness, while sand on hard bottom habitats (<0.4 ha MMU) contributed an additional $13.4 \%$ and had a negative relationship with species richness (Table 8A). Rugosity accounted for $62.5 \%$ of the variability in number of individuals and was the only parameter included in the model selection (Table 8B). Nearly $52 \%$ of the variance in fish biomass within MLCDs was explained by rugosity. The variance in depth, which describes larger scale measures of habitat complexity or rugosity, explained $8.2 \%$ of the vari-

abundant by weight within MLCD compared to open areas (Table 7C). High variance, small sample sizes, and overall low biomass within this habitat type contributed to the lack of statistical significance.

Herbivore biomass showed a significant negative relationship with macroalgal cover for both MLCDs $(\mathrm{r}=-0.70, \mathrm{p}=0.011)$ and open areas $(\mathrm{r}=-0.82, \mathrm{p}=$ 0.0011) (Fig. 5). The highest macroalgae cover in the MLCDs was found at Waikiki and Moku o Loe, where invasive algae such as Gracilaria salicornis and Kappaphycus spp. have proliferated. The Waiopae MLCD

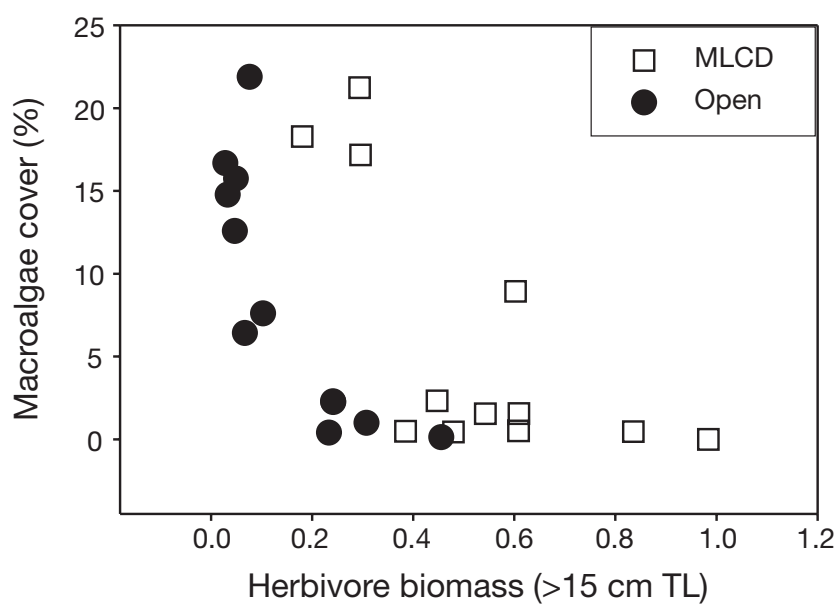

Fig. 5. Comparison of mean percent macroalgae cover and mean herbivore biomass (t ha ${ }^{-1}$ ) within protected (MLCD) and open (Open) areas ability in biomass. Macroalgae was negatively correlated with biomass and explained an additional 11.9\% of the variability in this parameter (Table 8C). There were no significant correlations between age of the protected areas and fish biomass, species richness, or number of individuals (Spearman's rho: $p>0.05$ for all).

\section{DISCUSSION}

Unique fish assemblages were observed among different habitat types and between different fisheries management regimes within specific habitat types. $\mathrm{CHB}$ and UCH habitats had more species, more individuals, and higher biomass than MAC and UCS habitats. Within habitat types, assemblage characteristics were typically higher for MLCDs compared with adjacent fished areas emphasizing the importance of protection from fishing regardless of habitat type. Although habitat quality in a few MLCDs is higher than adjacent areas, overall comparisons between all MLCDs and adjacent areas showed little difference and suggest that differences in fish assemblage structure between MLCDs and open access areas were not attributed to differences in habitat quality, but rather differences in other factors, such as fishing pressure (Friedlander et al. 2007).

Apex predators have been severely overexploited in the MHI (Friedlander \& DeMartini 2002) and this trophic group showed the greatest difference in abun- 
Table 8. Stepwise multiple regression analyses for fish assemblage characteristics among all MLCDs. Input values are means for each location. UCS was excluded due to the absence of this habitat type in many MLCDs. Probability to enter the model was 0.25 and probability to leave was 0.10 . Model selection criterion based on Mallow's $C_{p}$ criterion for selecting a model. Percent cover data were arcsinesquare root transformed prior to analyses. Biomass and number of individuals $\ln (x+1)$ transformed for statistical analyses. VIF: Variance Inflation Factor

\begin{tabular}{|c|c|c|c|c|c|c|c|}
\hline Parameter & Estimate & Seq SS & $F$ ratio & $\mathrm{R}^{2}$ & $C_{p}$ & $p$ & VIF \\
\hline \multicolumn{8}{|c|}{ (A) Species richness } \\
\hline Depth & 1.38 & 190.15 & 13.40 & 0.639 & 0.56 & 2 & 1.19 \\
\hline Sand & -27.57 & 39.96 & 5.34 & 0.774 & -0.62 & 3 & 1.19 \\
\hline \multicolumn{8}{|c|}{ (B) Number of individuals } \\
\hline Rugosity & 0.10 & 0.81 & 16.68 & 0.625 & -1.37 & 2 & 1.00 \\
\hline \multicolumn{8}{|l|}{ (C) Biomass } \\
\hline Rugosity & 0.03 & 0.22 & 3.58 & 0.516 & -0.02 & 2 & 1.50 \\
\hline Macroalgae & -1.81 & 0.05 & 5.60 & 0.635 & 0.02 & 3 & 1.52 \\
\hline Variance in dept & th 0.01 & 0.04 & 2.32 & 0.717 & 0.67 & 4 & 2.12 \\
\hline
\end{tabular}

dance and biomass between MLCDs and fished areas. These predators and other large, mobile species may not be adequately surveyed using underwater visual census (UVC) techniques, and methods such as longlines and hook-and-line fishing are often used to estimate abundance for these species (Pikitch et al. 2005). Despite limitations to the method, UVCs have been found to be significantly and positively correlated with various fishing methods (e.g. longlining, line fishing) for reef fish stocks in New Caledonia (Kulbicki et al. 2000); we therefore feel that UVCs provide a robust relative comparison of predator biomass among sampling strata.

Although overall biomass was low in sand habitats, apex predators accounted for $62 \%$ of the biomass in this habitat within MLCDs. This highlights the importance of sand as a corridor for apex predators and the need to include sand habitats into reserve design. These corridors may provide transit pathways among hard bottom habitats or serve as important feeding locations for these top predators.

Several of the MLCDs (e.g. Waiopae, Moku o Loe) included shallow water habitats that were identified as important nursery areas for a number of fishes that make ontogenetic movements into deeper water habitats with age (Friedlander et al. 2007). Elsewhere in Hawaii, DeMartini (2004) has identified backreef, lagoonal patch reef, and other sheltered habitats as nursery areas for juveniles.

Rugosity explained the majority of the variability in species richness and biomass and also provides an important contribution to variation in number of individuals. When compared among areas of similar rugosity, protected areas harbored significantly greater biomass than areas open to fishing. Within MLCDs, rugosity explained most of the variability in number of individuals (62\%) and biomass (52\%). Variance in depth reflects a larger scale measure of complexity and explained slightly more than $8 \%$ of fish biomass among MLCDs.

MLCDs with greater depth ranges had greater species richness compared to shallower protected areas with narrower depth ranges. A broader depth range encompasses a greater range of habitat types, microhabitat variability, and reef complexity that harbors more diverse fish assemblages. The exclusion of deeper habitats from some MLCDs makes organisms that utilize these habitats for diel and ontogenetic movement vulnerable to exploitation.

Macroalgae cover had a negative relationship with a number of fish assemblage characteristics. There were strong negative relationships between the biomass of large herbivores and macroalgae cover for both MLCDs and areas open to fishing. The higher herbivore biomass in protected areas partially accounted for the lower overall macroalgae cover observed in these areas compared with fished areas. Macroalgae overgrows and reduces the structural complexity of the reef (Williams \& Polunin 2001); in particular, introduced and invasive algae have proliferated around the urban areas of Oahu and Maui (Smith et al. 2002) exacerbating the problem that overfishing of herbivores has created in these areas. Reduced biomass of herbivorous fishes as a result of overfishing is thought to contribute to the increase in macroalgae cover observed on many reefs around the world (Hughes 1994, Jackson et al. 2001), but is only one of many factors leading to phase shifts from coral to macroalgae on coral reefs (Hughes 1994).

Despite the fact that MPAs in Hawaii have been in existence since the 1960s, no comprehensive assessment has been conducted until now. Many MLCDs in Hawaii were initially established to support the State of Hawaii's conservation and education objectives, not to enhance fish stocks or conserve ecosystems. As a consequence, most are currently too small to provide these benefits. Their small size and limited habitat types do not allow for the entire fish assemblage to function in a natural manner (Friedlander et al. 2007). In addition, many of these MLCDs do not incorporate the range of habitats and depths that tend to have higher species richness and diversity. Inclusion of deeper habitats not only enhances the biodiversity of the protected area, but also protects critical habitats for larger-bodied fishes that undergo ontogenetic movements to deeper habitats with age (Lindeman et al. 2000). 
The concept of essential fish habitat (NOAA 1996) and the principles behind developing MPAs necessitate examination of greater spatial ranges than those at which typical experiments are conducted. The results of this study suggest that for future MPAs in nearshore waters in Hawaii to be effective, they should contain CHB habitats (live coral cover $>10 \%$ ) with low macroalgal cover $(<10 \%)$, high topographical complexity (rugosity $>1.5$ ), access to UCS habitats, and a wide range of depths (e.g. 0 to $30 \mathrm{~m}$ ).

Analysis of reef fish distribution among all habitats available in the seascape is critical to developing better informed resource management solutions. Habitat plays an important role in structuring fish assemblages, yet most studies of marine reserves fail to measure habitat quality (Côte et al. 2001). In a review of 89 marine reserve studies, Halpern (2003) acknowledged that differences in habitat characteristics among reserves made comparisons and analyses difficult. In one of the few studies to examine reserve habitat, McClanahan (1994) found that given equal habitat quality, reserves in Kenya had significantly more species than non-reserve areas.

The landscape process approach focuses in large part on providing corridors to link networks of protected areas (Rosenberg et al. 1997). Marine reserve networks have the greatest chance of including all species, life stages, and ecological linkages if they encompass representative portions of all ecologically relevant habitat types in a replicated manner (Sala et al. 2002). Habitats are a good surrogate for species, so a system of protected areas that incorporates all habitat types is likely to also provide refuge for most species (Ward et al. 1999, Sala et al. 2002, Friedlander et al. 2003b). In fact, habitats are generally a better focus for protected area design than species because they are easier to map and are more closely tied to the ecological processes that should ultimately be conserved (Sladek Nowlis \& Friedlander 2005).

Recently, spatially explicit biogeographic assessments have provided robust analytical results to strengthen the sustainable management of marine resources within and adjacent to MPAs (Monaco et al. 2005, Monaco et al. 2007). A logical progression of events leading to the establishment of an MPA would first include an assessment of the function of available habitats relative to managed fishery resources. The high variance in fish assemblage characteristics among different habitat types and the unique fish assemblages associated with these different habitats means that sampling and analyses need to be stratified by habitat for more robust statistical comparisons.

MPA design must consider the habitat requirements and life histories of the species of interest as well as the extent of fishing pressure in the adjacent area.
Enforcement must be effective to achieve the goals of the MPAs, and the design of the protected area should consider how to maximize enforcement. Future protected area design in the MHI needs to incorporate a mosaic of habitats to support viable reef fish populations. Complex habitats will harbor higher biomass and greater species richness. Shallow nearshore habitats are necessary for recruit settlement and juvenile survival, while deeper habitats are important foraging, sheltering, and spawning sites for large adults. To more effectively sample organisms across the seascape and examine habitat utilization patterns, complementary methods that incorporate movement patterns and alternative sampling methods need to be employed (Chapman et al. 2005).

\section{CONCLUSIONS}

This study demonstrates that certain habitat qualities (e.g. high rugosity, large depth range, and low macroalgal cover) in addition to protection from fishing appear essential to enhancing fish assemblages in Hawaii. By identifying essential fish habitat and other sensitive and important habitats, MPAs can be designed to maximize protection for vulnerable life stages (Lindeman et al. 2000). Exclusion of these essential habitats would most certainly impose a bottleneck at which population and growth potential might be compromised (Christensen et al. 2003).

Conservation and ecosystem issues will dominate fisheries management in coming years. Hopefully this will focus a greater amount of effort on conserving entire ecosystems and the variety of all habitats that constitute them. The integration of mapping and monitoring of coral reef ecosystems and reef fish habitat utilization patterns can help managers make informed decisions about MPA design and effectiveness, as well as helping to define essential fish habitat and ecosystem function. Spatial information is often underutilized owing to the lack of capability to explore spatial and temporal relationships between species distributions and environmental gradients across large spatial scales (Battista \& Monaco 2004). The approach taken in this study, which attempts to make a functional match between habitats and fishes to be preserved, is appropriate for selecting, evaluating, and managing reserves and should aid in decisions regarding existing and future MPAs.

Acknowledgements. We thank A. Clark from Hawaii DLNR/ DAR for providing support in all aspects of this work. Field support from DAR was provided by G. Aeby, B. Carmen, S. Hau, J. Leonard, A. Ligon, R. Sparks, B. Walsh, and R. Young. Additional field support was provided by the University of Hawaii (K. Peyton, P. Jokiel, F. Cox, K. Rodgers, 
K. Uchino, W. Smith, and E. Muse), Maui Community College (D. Brown), and L. and K. Flanders. T. Battista, S. Rohman, and K. Buja of NOAA/NOS/CCMA-Biogeography Branch provided logistical and technical support during all aspects of this project. L. Wedding of University of Hawaii, Manoa provided invaluable GIS support and assisted greatly with the figures. This project was funded by NOAA's Coral Reef Conservation Program and National Centers for Coastal Ocean Science-Center for Coastal Monitoring and Assessment.

\section{LITERATURE CITED}

Appeldoorn RS, Friedlander A, Sladek Nowlis J, Usseglio P, Mitchell-Chui A (2003) Habitat connectivity in reef fish communities and marine reserve design in Old Providence-Santa Catalina, Colombia. Gulf Caribb Res 14: $61-78$

Battista TA, Monaco ME (2004) Geographic Information Systems applications in coastal marine fisheries. In: Fisher WL, Rahel FJ (eds) Geographic Information Systems in fisheries. American Fisheries Society, Bethesda, MD, p 189-208

Bellwood DR, Hughes TP (2001) Regional-scale assembly rules and biodiversity of coral reefs. Science 292:1532-1534

Beukers JS, Jones GP (1997) Habitat complexity modifies the impact of piscivores on a coral reef population. Oecologia 114:50-59

Brock VE (1954) A preliminary report on a method of estimating reef fish populations. J Wildl Manage 18:297-308

Bros WE, Cowell BC (1987) A technique for optimizing sample size (replication). J Exp Mar Biol Ecol 114:63-71

Brown EK (2004) Reef coral populations: spatial and temporal differences observed at six reefs off West Maui. PhD thesis, University of Hawaii, Honolulu, HI

Brown EK, Cox E, Jokiel P, Rodgers K and others (2004) Development of benthic sampling methods for the Coral Reef Assessment and Monitoring Program (CRAMP) in Hawai'i. Pac Sci 58:145-158

Chapman DD, Pikitch EK, Babcock E, Shivji MS (2005) Marine reserve design and evaluation using automated acoustic telemetry: a case-study involving coral reef-associated sharks in the Mesoamerican Caribbean. Mar Technol Soc J 39:42-55

Christensen JD, Jeffrey CFG, Caldow C, Monaco ME, Kendall MS, Appeldoorn RS (2003) Cross-shelf habitat utilization patterns of reef fishes in southwestern Puerto Rico. Gulf Caribb Res 14(2):9-28

Clark R, Christensen JD, Monaco ME, Caldwell PA, Matthews GA, Minello TJ (2004) A habitat-use model to determine essential fish habitat for juvenile brown shrimp (Farfantepenaeus aztecus) in Galveston Bay, Texas. Fish Bull 102:264-277

Clarke K, Gorley R (2001) PRIMER v5.0: user manual/tutorial. Primer-E, Plymouth

Côte IM, Mosqueira I, Reynolds JD (2001) Effects of marine reserve characteristics on the protection of fish populations: a meta-analysis. J Fish Biol 59(Suppl A):178-189

Coyne MS, Battista TA, Anderson M, Waddell J and others (2003) Benthic habitats of the main Hawaiian Islands. NOAA Technical Memorandum NOS/NCCOS/CCMA 152. US Department of Commerce, National Oceanic and Atmospheric Administration, National Ocean Service, Silver Spring, MD

DeMartini EE (2004) Habitat and endemism of recruits to shallow reef fish populations: selection criteria for notake MPAs in the NWHI Coral Reef Ecosystem Reserve. Bull Mar Sci 74:185-205
Dulvy NK, Polunin NVC, Mill AC, Graham NAJ (2004) Size structural change in lightly exploited coral reef fish communities: evidence for weak indirect effects. Can J Fish Aquat Sci 61:466-475

Friedlander AM, DeMartini EE (2002) Contrasts in density, size, and biomass of reef fishes between the northwestern and the main Hawaiian islands: the effects of fishing down apex predators. Mar Ecol Prog Ser 230:253-264

Friedlander AM, Parrish JD (1998) Habitat characteristics affecting fish assemblages on a Hawaiian coral reef. J Exp Mar Biol Ecol 224(1):1-30

Friedlander AM, Brown EK, Jokiel PL, Smith WR, Rodgers SK (2003a) Effects of habitat, wave exposure, and marine protected area status on coral reef fish assemblages in the Hawaiian archipelago. Coral Reefs 22:291-305

Friedlander A, Sladek Nowlis J, Sanchez JA, Appeldoorn R and others (2003b) Designing effective marine protected areas in Seaflower Biosphere Reserve, Colombia, based on biological and sociological information. Conserv Biol 17: 1769-1784

Friedlander AM, Brown EK, Monaco ME (2007) Coupling ecology and GIS to evaluate efficacy of marine protected areas in Hawaii. Ecol Appl 17:715-730

Halpern BS (2003) The impact of marine reserves: do reserves work and does reserve size matter? Ecol Appl 13: S117-S137

Hawaii Division of Aquatic Resources (1992) Marine life conservation district plan. Hawaii Department of Land and Natural Resources, Honolulu, HI

Hughes TP (1994) Catastrophes, phase shifts and large-scale degradation of a Caribbean coral reef. Science 301:929-933

Hunter CL, Evans CW (1995) Coral reefs in Kaneohe Bay, Hawaii: two centuries of western influence and two decades of data. Bull Mar Sci 57:501-515

Jackson JBC, Kirby MX, Berger WH, Bjorndal KA and others (2001) Historical overfishing and the recent collapse of coastal ecosystems. Science 293:629-638

Kendall MS, Christensen JD, Hillis-Starr Z (2003) Multi-scale data used to analyze the spatial distribution of French grunts, Haemulon flavolineatum, relative to hard and soft bottom in a benthic landscape. Environ Biol Fish 66: $19-26$

Kleinbaum DG, Kupper LL, Muller KE (1988). Applied regression analysis and other multivariable methods. PWS-Kent Publishing, Boston, MA

Kulbicki M (1998) How acquired behaviour of commercial reef fish may influence results obtained from visual censuses. J Exp Mar Biol Ecol 222:11-30

Kulbicki M, Labrosse P, Letourneur Y (2000) Fish stock assessment of the northern New Caledonian lagoons: 2. Stocks of lagoon bottom and reef-associated fishes. Aquat Living Resour 13:77-90

Lindeman KC, Pugliese R, Waugh GT, Ault JS (2000) Developmental patterns within a multispecies reef fishery: management applications for essential fish habitat and protected areas. Bull Mar Sci 66(3):929-956

Mallows CL (1973) Some comments on $C_{p}$. Technometrics 15: 661-675

McClanahan TR (1994) Kenyan coral reef lagoon fish: effects of fishing, substrate complexity, and sea urchins. Coral Reefs 13:231-241

Monaco M, Kendall M, Higgins J, Alexander C, Tartt M (2005) Biogeographic assessments of NOAA National Marine Sanctuaries: the integration of ecology and GIS to aid in marine management boundary delineation and assessment. In: Wright DJ, Scholz AJ (eds) Place matters: geospatial tools for marine science, conservation, and management 
in the Pacific Northwest. Oregon State University Press, Corvallis, OR, p 2-13

Monaco ME, Friedlander AM, Caldow C, Christensen JD and others (2007) Characterizing reef fish populations and habitats within and outside the US Virgin Islands Coral Reef National Monument: a lesson in MPA design. Fish Manag Ecol 14:33-40

NOAA (1996) Magnuson-Stevens fishery conservation and management act, as amended through October 11, 1996. NOAA Technical Memorandum NMFS-F/SPO-23

Pandolfi J, Jackson JBC, Baron N, Bradbury RH and others (2005) Are US coral reefs on the slippery slope to slime? Science 307:1725-1726

Parrish JD (1989) Fish communities of interacting shallow water habitats in tropical oceanic regions. Mar Ecol Prog Ser 58:143-160

Pikitch EK, Santora C, Babcock EA, Bakun A and others (2004) Ecosystem-based fishery management. Science 305: 346-347

Pikitch EK, Chapman DD, Babcock EA, Shivji MS (2005) Habitat use and demographic population structure of elasmobranchs at a Caribbean atoll (Glover's Reef, Belize). Mar Ecol Prog Ser 302:187-197

Reed SA (1980) Sampling and transecting techniques on tropical reef substrates. In: Environmental survey techniques for coastal water assessment. University of Hawai'i Sea Grant College Program. Sea Grant Cooperative Report UNIHI-SEAGRANT-CR-80-01:71-89

Risk MJ (1972) Fish diversity on a coral reef in the Virgin Islands. Atoll Res Bull 193:1-6

Editorial responsibility: Charles Birkeland (Contributing Editor), Honolulu, Hawaii, USA
Rosenberg DK, Noon BR, Meslow EC (1997) Biological corridors: form, function, and efficacy. BioScience 47:677-687

Sala E, Aburto-Oropeza O, Paredes G, Parra I, Barrera JC, Dayton PK (2002) A general model for designing networks of marine reserves. Science 298:1991-1993

Sebens KP (1991) Habitat structure and community dynamics in marine benthic systems. In: Bell SS, McCoy ED, Mushinsky HR (eds) Habitat structure: the physical arrangement of objects in space. Chapman \& Hall, New York, p 211-234

Sladek Nowlis J, Friedlander AM (2004) Marine reserve design and designation process. In: Sobel J, Dahlgren C (eds) Marine reserves; their science, design and use. Island Press, Washington, DC, p 128-163

Sladek Nowlis J, Friedlander AM (2005) Marine reserve design and function for fisheries management. In: Norse EA, Crowder LB (eds) Marine conservation biology: the science of maintaining the sea's biodiversity. Island Press, Washington, DC, p 280-301

Smith JE, Hunter CL, Smith CM (2002) Distribution and reproductive characteristics of nonindigenous and invasive marine algae in the Hawaiian Islands. Pac Sci 53:299-315

Ward TJ, Vanderklift MA, Nicholls AO, Kenchington RA (1999) Selecting marine reserves using habitats and spatial assemblages as surrogates for biological diversity. Ecol Appl 9:691-698

Williams ID, Polunin NVC (2001) Large-scale associations between macroalgal cover and grazer biomass on middepth reefs in the Caribbean. Coral Reefs 19:358-366

Zar JH (1999) Biostatistical analysis, 4th edn. Prentice Hall, Upper Saddle River, NJ

Submitted: October 6, 2006; Accepted: June 1, 2007 Proofs received from author(s): November 2, 2007 